\title{
Relatos y metáforas en la estructura cognitiva de la exclusión social ${ }^{*}$
}

\author{
Stories and metaphors in the cognitive structure \\ of the social exclusion \\ Relatos e metáforas na estrutura cognitiva \\ da exclusão social
}

Recibido el 5 de octubre de 2015. Aceptado el 14 de diciembre de 2015

\author{
Ricardo Arrubla Sánchez** \\ Colombia
}

\section{Resumen}

Objetivo: identificar los tipos de exclusión en los referentes cognitivos que son representados a través del lenguaje en las relaciones sociales y su concordancia con la semántica de la violencia y el

, Para citar este artículo: Arrubla Sánchez, Ricardo. Relatos y metáforas en la estructura cognitiva de la exclusión social. Ánfora, 22(39), 203-229. Universidad Autónoma de Manizales. ISSN 0121-6538. manejo de las emociones irracionales. Metodología: estudio cualitativo - deductivo con método documental y registro de actos de habla para la identificación de categorías semánticas y léxicas articuladas al eje central: exclusión, discriminación y otras formas de violencia verbal. Resultados: se identificó la existencia de estructuras excluyentes en el lenguaje, las cuales se han manejado como un hecho cultural y están presentes en formas semánticas y pragmáticas, tales como: el

\footnotetext{
* Este artículo es resultado de la investigación: "La transformación cognitiva a partir del lenguaje afirmativo para la paz", adelantada dentro del marco del proyecto Fortalecimiento de Procesos Académicos y Administrativos de Educación Superior con Enfoque de Educación Inclusiva con el Ministerio de Educación y el Observatorio para la Paz.

** Magíster en Administración de Organizaciones. Docente Investigador de la Fundación Universitaria del ÁreaAndina Sede Bogotá,Colombia.Correo electrónico: rarrubla@areandina.edu.co y jessieconsultores@ hotmail.com.
} 
manejo de los duales aparentes, el uso de diminutivos o adjetivos, el camuflaje de las cogniciones distorsionadas y la disimetría en los discursos. Conclusiones: se concluye que estructuras excluyentes enraizadas en el lenguaje son expresadas a través de los relatos y metáforas que los individuos y comunidades construyen para representarse y hablar en su vida cotidiana. Su construcción lógica actúa como un dispositivo de defensa en un contexto violento que revalida dichas formas de expresión e impide que se pueda incorporar un pensamiento que conduzca a relaciones más humanas de igualdad y tolerancia.

Palabras Claves: Metáforas, Metacognición, Cultura, Transformación, Violencia, Pensamiento.

\section{Abstract}

Aim: to identify the types of exclusion in the cognitive referents that are represented through language in social relations and their concordance with the semantics of violence and the management of irrational emotions. Methodology: qualitative deductive study with a documentary method and recording of speech acts to identify the semantic and lexical categories articulated to the main axis: exclusion, discrimination and other forms of verbal violence. Results: the existence of selective structures in the language was identified. These structures have been managed as a cultural fact and are present in semantic and pragmatic forms, such as: the management of apparent duals, the use of diminutives or adjectives, the camouflage of distorted cognitions and the dissymmetry in speeches. Conclusions: it is concluded that selective structures rooted in the language are expressed through the stories and metaphors that individuals and communities build to represent themselves and speak in their daily lives. Its logical construction acts as a defense mechanism in a violent context that confirms those forms of expression and impedes to incorporate a thought that leads to more human relationships of equality and tolerance.

Keywords: Metaphors, Metacognition, Culture, Transformation, Violence, Thought.

\section{Resumo}

Objetivo: identificar os tipos de exclusão nos referentes cognitivos que são representados a través da linguagem nas relações sociais e sua concordância com a semântica da violência e o controle das emoções irracionais. Metodologia: estudo qualitativo - dedutivo com método documental e registro de atos de fala para a 
identificação de categorias semânticas e léxicas articuladas ao eixo central: exclusão, discriminação e outras formas de violência verbal. Resultados: identificou-se a existência de estruturas excludentes na linguagem, as quais foram manipuladas como um fato cultural e estão presentes em formas semânticas e pragmáticas, tais como: a gestão dos duais aparentes, o uso de diminutivos ou adjetivos, a camuflagem das cognições distorcidas e a dissimetria nos discursos. Conclusões: concluiu-se que estruturas excludentes enraizadas na linguagem são expressas a través dos relatos e metáforas que os indivíduos e comunidades constroem para se representar e falar em sua vida cotidiana. Sua construção lógica age como um dispositivo de defesa em um contexto violento que revalida tais formas de expressão e impede que se possa incorporar um pensamento que conduza a relações mais humanas de igualdade e tolerância.

Palavras Chaves: Metáforas, Metacognição, Cultura, Transformação, Violência, Pensamento. 


\section{Introducción}

El entorno actual de la sociedad ha generado cambios profundos en la cultura, los individuos y su forma de pensar. Cuando se produce un cambio en una sociedad su estructura se altera, ya que emergen nuevas relaciones internas, surgen nuevos actores sociales, razones diferentes justifican la movilización y acción colectiva, así como nuevos intereses de desarrollo y nuevos enfoques políticos.

Autores como Tarrow (2004) y Dieter Rucht (1999) plantean la existencia de un contexto ampliado que incorpora aspectos socioeconómicos, culturales y smbólicos, inmersos en las nuevas relaciones sociales, que impulsan la movilización individual y colectiva y la busqueda de oportunidades, en lógicas que han incorporado tanto los intereses económicos como políticos.

Estas lógicas empoderadas, afirma Martín-Barbero (2007), son fruto de una memoria histórica anatagónica al relato de nación oficialista (que tiene tendencia de clase, raza, y género) y que se sustenta sobre las desigualdades sociales acumuladas del pasado. En la actualidad adquieren un rostro sobre las políticas de identidad, de la diferencia colectiva y del reconocimiento grupal al tiempo que replantean el sentido de las relaciones sociales desde la política y de lo público, dando lugar a un nuevo tipo de sujetos políticos. La dinámica de tales luchas por el reconocimiento van transformando los patrones culturales de interpretación, comunicación y representación (Fraser, 2007), pero tristemente desde la deslegitimización del discurso del otro. Las mencionadas luchas por el reconocimiento entran en la esfera pública democrática para pluralizarla y ejercitar la interculturalidad, pero es preciso desmontar primero (desde la transformación cognitiva) los dispositivos de odio y violencia con los que han sido cargados, para que los patrones sociales de representación, interpretación y comunicación, permitan la presentación del relato de historias de sí mismo y del otro, en lugar de conducir a la balcanización o una definitiva separación cultural.

Al realizar una mirada analítica a las condiciones estructurales del lenguaje, podemos identificar que existen diferentes tipologías de textos, frases y palabras, que subyacen en los cimientos simbólicos de la cultura y en referentes que la ratifican como una posibilidad siempre manifiesta de construir caminos para eliminar la exclusión social y la violencia.

Estos mecanismos están anclados en el lenguaje cuya finalidad es la de producir diferentes percepciones y estados psico-emocionales, que permitan controlar los impulsos y la agresividad humana y propiciar el uso de la razón, el diálogo y el 
equilibrio interno de las emociones. Por esto, resulta fundamental, identificar y analizar la importancia de dichos referentes, con el fin de producir unos nuevos, ya que los cambios culturales y el uso frecuente de dicho lenguaje puede generar un desgaste en sus efectos socio-emocionales y cognitivos. Hay que entender que el lenguaje es como un organismo vivo y, por lo tanto, sometido a la erosión del tiempo y el desgaste por el uso. En el lenguaje las palabras también mutan su sentido y cambian el contexto, y con ello su significado.

Según Hymes (1972), el conjunto de sistemas subyacentes de conocimientos y habilidades necesarios para la comunicación actualizada o, según Gumperz (1964), lo que un sujeto necesita saber para comunicarse eficazmente en contextos culturalmente significantes es una serie de subcompetencias, estas son: discursiva o textual, gramatical, sociolingüística, referencial o enciclopédica, literaria, sociocultural, de aprendizaje. Las cuales según los investigadores están mediadas por la memoria, memoria a corto plazo (Miller, 1956); modelo del flujo de información con filtros selectivos (Broadbent, 1958, 1983); evidencia de almacenamientos sensoriales (Sperling, 1966); modelo de memoria de almacenamiento múltiple (Atkinson y Shiffrin, 1968); modelo de memoria de trabajo (Baddeley y Hitch, 1974); modelo de memoria cultural (Lave y Wenger, 1991; Wertsch, 1991; Salomon, 1993; Wertsch, Del Río, Álvarez, 1995; Pozo, 2001).

A partir de una serie de hallazgos sobre una amplia gama de tareas primarias tales como razonamiento, comprensión, aprendizaje, Baddeley y Hitch (1974) concluyeron que, aun cuando el Almacén a Corto Plazo (ACP) planteado por Atkinson y Shiffrin trabaja con una carga de memoria cercana al límite de su capacidad -recuerdo serial de 6 dígitos-, su deterioro no es tan dramático, pero se va produciendo de forma paulatina a medida que va ingresando nueva información que a su vez se convierte en memoria de trabajo.

Estos hechos impiden que el individuo se convierta en productor de narraciones de inclusión, constructor de sentido y productor de historia, afectando su relación con el contexto y los factores que pueden llevarlo a la construcción de un modelo de memoria cultural.

También habría que relacionar aspectos de tipo psicológico interno como el desgaste emocional, que produce un distanciamiento afectivo como forma de protección del yo, aburrimiento y actitud cínica, impaciencia e irritabilidad, desorientación, sentimiento de impotencia, incapacidad de concentración y sentimientos depresivos. La despersonalización o deshumanización se caracteriza por tratar a las personas como objetos o simplemente se mantienen relaciones 
con ellos de manera instrumental. Las personas demuestran o mantienen una comunicación estratégica o enmascarada en la que prevalece el cinismo o la disimulación afectiva.

En esta medida, la investigación aporta información relevante sobre las estructuras cognitivas de violencia que se han incorporado en el lenguaje, y que se emplean como detonadores en el lenguaje cotinidado, y que por estar presentes en nuestros actos de habla informales, no le damos la debida importancia. Por tal razón, el artículo busca identificar palabras, frases y vocabulario presentes en las conversaciones humanas, que tengan una connotación violenta o que sean producto del pensamiento irracional o de las emociones irracionales, para proponer sustiuirlo por el uso de un lenguaje afirmativo para la paz.

El fenómeno de la violencia simbólica del lenguaje está presente en la cotidianidad cultural, inclusive en la polisemia de las ciencias sociales en torno a conceptos como la "sociedad de estratos", representada en categorías como "los de arriba" y "los de abajo" producto de la desigualdad humana que se manifiesta en el lenguaje cotidiano. Así, el problema de las metáforas y narraciones es un problema social puesto que la comunicación lingüística relativiza todos los demás factores, y a pesar de que las personas no viven en el plano físico unos por encima de otros, tales teoremas adquieren realidad porque toman validez del lenguaje en la forma como las personas se relacionan.

Por lo que indagar en tales aspectos, permitirá comprender como se manifiestan las estructuras del lenguaje en el esquema de clases, por ejemplo en las escuelas básicas y secundarias, donde los niños con dificulades de aprendizaje se envían a las "escuelas especiales" para recibir un tratamiento especial. Sin duda, en ninguna otra parte se evidencia con tanta claridad la violencia simbólica de los principios abstractos de organización como en el caso de la escuela especial, en la que el tratamiento especial conduce siempre a un tipo cualquiera de privación, crea distancia social, por las burlas de sus compañeros y, en última instancia, frente a la conducta de los padres, sobre todo si éstos son de "los que quieren subir" o escalar peldaños en la "escalera" social.

El interés principal de la investigación fue identificar los tipos de exclusión presentes en los relatos y metáforas sociales realizandos en los actos de habla en conversaciones contidianas, registrar las frases y palabras con una carga semántica de exclusión, y analizar su relación con los factores estructurales de la cultura, y los cambos de lógica en una sociedad de mercado globalizado. Finalmente, establecer las implicaciones de las estructuras del lenguaje excluyente con los funcionamiento cognitivos de la mente humana. 


\section{Metodología}

Para comprender dicho fenómeno, es necesario interpretar las nuevas formas de acción organizativa de las comunidades, su manera de expresar las emociones e interactuar; lo cual puede hacerse desde las matrices conceptuales de habla, para comprender su estructura y los propósitos que cumple. Es así que para lograr la efectividad de los nuevos procesos organizativos, los indivudos y la sociedad misma, deben tener la capacidad de observarse, interpretar y modificar sus discursos, y con ello modificar sus estructuras de pensamiento.

El enfoque del artículo es de carácter analítico - deductivo con método documental. Se basa en el estudio de documentos para el conocimiento de la verdad, y en el registro de conversaciones informales, y actos de habla.

$\mathrm{Su}$ técnica consiste en localizar las fuentes documentales, elaborar fichas, catálogo, y gráficas relacionados a dichas fuentes documentales, integrar una bibliografía de consulta relativa al tema a investigar, registrar los datos importantes o trascendentales que se encuentran mediante notas o fichas bibliográficas. Con el uso del cuaderno de apuntes, realizar registros de las conversaciones, frases y palabras que tengan connotación y referentes a la violencia de los símbolos sociales.

Unidades de Análisis: Serán todos los textos (artículos) que se puedan reseñar dentro del eje temático: Violencia, lenguaje y exclusión. Se realizará una primera búsqueda abierta con el objetivo de tener una base de textos bastante amplia, para luego seleccionar los más representativos.

Las unidades de registro: La UR es aquella fracción del texto o acto de habla que será seleccionada como significante y que será registrada (transcrita en una ficha). Para el caso de la investigación se realizará a través de núcleos de significado, o sea cada frase, oración o párrafo ("proposición") que sean significativos, válidos para lo que se está buscando.

Variables: Las variables empleadas durante la investigación fueron: pseudolenguaje de la violencia de género, violencia afectivo-sexual, agresión, incomunicación, desorganización, permisividad, impunidad, anomia, pensamiento irracional, y emociones irracionales. 
Tabla 1. Procedimiento

\begin{tabular}{|c|}
\hline Elección del tema \\
\hline Acopio de bibliografía básica sobre el tema \\
\hline Elaboración de fichas bibliográficas y hemerográficas \\
\hline Lectura del material \\
\hline Delimitación del tema \\
\hline Elaboración del esquema de trabajo \\
\hline Ampliación del material sobre el tema ya delimitado \\
\hline Lectura minuciosa de la bibliografía \\
\hline Elaboración de fichas de contenido \\
\hline Organización de las fichas de contenido y revisión del esquema \\
\hline Elaboración de cuaderno de apuntes \\
\hline Organización definitiva del fichero \\
\hline Redacción del trabajo final \\
\hline
\end{tabular}

Fuente: Elaboración propia

Análisis de la información: De acuerdo con Rodríguez y Valldeorio, el análisis de datos consiste en dar sentido a la información recopilada, requiriendo una buena organización por parte de este. Así mismo los autores precisan pasos a seguir en el análisis de datos son: "Leer los datos repetidamente, seguir las pistas de temas, intuiciones, interpretaciones e ideas, buscar temas emergentes, elaborar tipologías, desarrollar conceptos y proposiciones teóricas, leer material bibliográfico, desarrollar una guía de la historia" (Taylor y Bodgan, 2002, pp. 160-167) lo cual se tuvo en cuenta para interpretar la información, y sacar conclusiones de la misma.

\section{Resultados}

A partir de interpretar la información teórica con categorias como cultura, posmodernidad, exlusión, lenguaje, narración y metáforas se realizó una disertación sobre los cambios operados en la sociedad y sus implicaciones en la permanencia y uso de estructuras de violencia y exclusión social incorporadas en la forma como nos expresamos. La cual se presentará en los siguientes acápites del texto: Rostros, máscaras y mascaradas que analiza los factores estructurales de la cultura y los cambios de lógica desde la sociedad del mercado 
globalizado; La dimensión estética de la ideantidad relaciona el vínculo que hay entre la comunidad y las propiedades semántias de los relatos; Las estructruras excluyentes del lenguaje identifican las frases con una carga de exclusión y los tipos de exclusión presentes en los relatos; Tan cerca, tan lejos: la distancia social establece que el resultado de las metáforas de exclusión en los actos de habla de conversaciones cotidianas crea representaciones cognitivas de pensamiento que se vuelven fronteras físicas y simbólicas de exclusión en las relaciones humanas; Submundos, suburbios y marginalizados plantea que en las lógicas verbales de exclusión se contruyen metáforas espaciales para focalizar la marginalización y territorializarla; finalmente, El lenguaje de exclusión y su funcionamiento cognitivo afirma que las formas de expresión y de habla son el resultado de los patrones fonológicos, gramaticales y léxico-semánticos de la lengua.

\section{Rostros, máscaras y mascaradas}

Pensar la sociedad en la actualidad, implica comprender que su rostro tiene dos caras. Coexisten dos tipos societales, que se complementan y a su vez se contradicen. La sociedad industrial del Estado nacional, y la sociedad postindustrial globalizada. Dicha desarticulación fractura las relaciones entre Estado, representación y sociedad civil, desde su esencia ideológica, proveniente de las bases de tipo nacional-popular y político-céntrico, junto con una búsqueda que proviene de todos los sectores, y que intenta adaptarse a las nuevas tendencias mundiales.

Ello conduce a un cambio en la interpretación de la sociedad, ya no entendida desde la existencia de una estructura como elemento determinante en la vida social y colectiva, sino pensada en las nuevas relaciones de mercado, dadas por el consumo, y la reclamación de derechos indivuales. Desde la fuerza de las políticas públicas, y la injerencia de las instituciones en las realidades locales, la acción colectiva se configura principalmente a través de cuatro ejes: la democratización política, la formación ciudadana, la reconstrucción de las economías nacionales, y la defensa de la subjetividad cultural.

El análisis estructural de la sociedad proviene de teóricos como Durkheim y Marx, cuyas ideas básicas han resultado complementarias en una larga serie de investigaciones a lo largo de los años, que van desde las fuentes socialesestructurales de la conducta desviada y la formación de la personalidad burocrática hasta el desarrollo y la estructura institucional de la ciencia. "el conjunto de los modos en que las prácticas de grupos e individuos están organizadas (instituciones) y relacionadas entre sí (procesos sociales), de manera que se crean 
unos ejes de desigualdad que configuran la identidad de esos individuos y grupos, así como los cursos posibles de la acción social (individual y colectiva). Dicho de otro modo, la estructura social sería la configuración de instituciones, reglas y recursos capaces de atribuir condiciones de vida desiguales a las personas en un momento y un lugar determinados”. José Adelantado y otros (1999).

Una de las características de las nuevas formas de acción social, es la construcción de sus relatos, los cuales dan identidad y motivan las formas de organización y movilidad social, ya que así le dan sentido a su vida. Son las explicaciones y narraciones una producción subjetiva que fundamenta las actitudes, emociones, acciones e interpretaciones de la realidad, y las diversas situaciones que percibe un individuo y comparte con una colectividad. Por lo que los individuos, actuan, emocionan e interpretan desde relatos. En este sentido, el relato se presenta como una narración, discuso, historia o cuento estructurado a partir de un conjunto de significados, metáforas y simbolos, empleados para dar sentido a los acontecimientos de la experiencia y a la interpretación del mundo.

Según Charaudeau (2011) "las creencias están constituidas por un saber polarizado en torno de los valores socialmente compartidos; el sujeto moviliza una o varias redes inferenciales propuestas por los universos de creencia disponibles en la situación en la que se encuentra, lo que es susceptible de desencadenar en él un estado emocional. El desencadenamiento del estado emocional (o su ausencia) lo pone frente a una sanción social que desembocará en diversos juicios de orden psicológico o moral”.

De esta manera, lo que un inviduo dice, lo dice desde su relato: sus acciones, emociones e interpretaciones son representaciones de los relatos que tiene incorporados, y que a su vez aparecen y se desarrollan como producto de la interacción humana, de su experiencia con el entorno, y del intercambio entre individuos a través del lenguaje. Su construcción es colectiva, en terminos de Viven Burr (2002) “cuando las personas hablan entre sí, el mundo se construye” (p. 7).

Se puede afirmar entonces, que la realidad se interpreta a partir de los relatos que las personas elaboran, los cuales a su vez son influidos por las diferentes opiniones durante los actos de habla, por lo que los realtos pueden ser transformados, cambiados y nuevamente reelaborados con el lenguaje, y por la influencia de la realidad y su efecto emocional. Los relatos surgen como construcciones colectivas que a partir de las vivencias diarias con las demás personas dan sentido a las actividades, y edifican una realidad social. Por estas razones se habla de relato social, como una forma de discurso social que posee el grupo de personas que conforman una comunidad y con base en la cual 
interpretan, emocionan y actúan en un dominio específico.

Para el antropólogo Cliffor Geertz (1992) "El hombre es un animal inserto en tramas de significado que él mismo ha tejido", y considera que "la cultura es esa urdimbre y que el análisis de la cultura ha de ser por lo tanto, no una ciencia experimental en busca de leyes, sino una ciencia interpretativa en busca de significaciones" (p. 20).

Por medio del relato, se organiza la experiencia humana, la cual se construye dentro de un espacio territorial y al interior de una comunidad o grupo social, quien a partir del lenguaje realiza una construcción de representaciones simbólicas que le dan sentido a las experiencias colectivas. La vida de la comunidad se instituye de manera narrativa, al relatar su vida, su experiencia se vuelve discurso presente en la representación que construye de sí misma.

Para García Canclini (1995, p. 107) cada individuo está inscrito en un relato social, producto de su experiencia y búsqueda de sentido, pero es la identidad "una construcción que se relata”. La identidad como relato es una narración grupal, un sistema de significaciones o, como afirma Lozano (1982, p. 33) es un proceso semiótico (Roland, 1980)". Es "una galaxia de significaciones, no tiene comienzo; es reversible, se accede a él a través de múltiples entradas" (Barthes, 1980, p. 3).

En la dimensión identitaria se pueden encontrar significados de referencia común a todos los grupos sociales o comunidades, desde luego cada uno tiene su forma particular de experiencia y trayectoria, que manifiesta a través de relatos relativamente distintos. Dentro de esta categoría, según los teóricos del multiculturalismo como Will Kymlicka existen tres tipologías de grupos, que reclaman derechos a partir de la reafirmación de sus discursos y narraciones: i) grupos desfavorecidos que requieren derechos especiales de representación, ii) grupos religiosos y de inmigrantes y, iii) las minorías nacionales que requieren derechos de autogobierno (Kymlicka, 1996).

Estos sujetos se ven envueltos en dinámicas complejas propias de los reconocimientos políticos culturales, y de las ciudadanías diferenciadas que maneja el gobierno, y que hacen parte de las disputas por acceder a derechos, recursos y beneficios, y cambiar las lógicas de los imaginarios sociales, jerarquizados y prejuiciados (Martín-Barbero, 2007). Ello implica, reconocer el papel que juega la identidad como dimensión estética en la defensa y construcción de las metáforas sociales, factor que se analizará a continuación. 


\section{La dimensión estética de la identidad}

La identidad comunitaria determina el nivel de su estructura organizacional, mediante los diferentes relatos y discursos de sus integrantes, así como de los interesados en ella, y el propósito común de sus relaciones, en particular mediante la interacción a través del entretenimiento, deporte, ocio, y las relaciones comerciales.

La identidad de la comunidad es construida por relatos que tienen las propiedades de ser múltiples y contingentes, y determinan las actividades en las cuales se actúa, emociona e interpreta. Así, cuando se estima que una comunidad es "rumbera" y se establece a través de ciertos discursos, sus habitantes se verán condicionados por está connotación, y las experiencias que surgen de ella. En este sentido, Leopoldo Múnera Ruiz afirma que el análisis de la historia de la formación del Estado en Colombia ha permanecido dominada por los enfoques teleológico y normativo, "reforzando los discursos e imaginarios de los cuatro dirigentes de las burocracias estatales, de las élites o grupos que se disputan el control del Estado para poner en marcha sus proyectos sociales" (Múnera, 2008). Con ello se ejerció una fuerza desestructurante hacia los discursos, metáforas y narraciones de las personas que conformaron las clases sociales pobres, la cual representaba la identidad de artesanos, obreros, negros, e indios.

Sin duda, los relatos que se construyen de sí mismos, pueden ser modificados de acuerdo con los cambios de los discursos del entorno y por las necesidades mismas de la comunidad, que obedecen a posiciones sociales, los marginados favorecen sus metáforas con la violencia, la desobediencia, la ilegalidad, y el tropo de víctimas, explotadas y sometidas, mientras que las clases sociales que tienen cierto nivel económico, narran sus experiencias desde zonas de privilegio y fuero legítimo. Así, muchos discursos marginales se pronuncian contra la violencia, drogadicción, machismo, sexismo, homofobia, y otros problemas arraigados a la cultura, pero también es sabido que muchas manifestaciones estéticas urbanas producto de comunidades emplean iconografía de los gánsteres de Hollywood "El Padrino" (The Gadfather) "Tony Montana" (Scarface) y demás personas que representan al crimen organizado en las películas, incluyendo a Pablo Escobar.

La socióloga Vionex Marti en el artículo "Lucrativo el baile del perro" afirma que: "los vídeos son una cristalización de la violencia, son una especie de teatro, después de todo es un show. Es un fenómeno urbano, pero con elementos rurales como el paternalismo y el machismo. Casi siempre sus símbolos apelan a lo trágico: muerte, violencia, desamor, etc. El lenguaje violento es un llamado a que me admires y me compres" (Pérez, 2008, p. 27). 
Todo esto puede ser observado para comprender el comportamiento de un grupo social, y su actuación e interpretación de la realidad, con el objetivo de encontrar posibles áreas de mejoría por la introducción de cambios en los discursos grupales o comunitarios.

Las acciones y actividades de los individuos, son guiadas por los discursos contemplados en la identidad de la comunidad, y si estos discursos cambian, la identidad cambia y la estructura cognitiva cambiaría también. Según la investigación de José Cabrera (1998), "los jóvenes se representan su espacio grupal como un lugar de experiencias nuevas (relaciones, prácticas, valores, perspectivas) las cuales les resultan muy significativas" (p. 239). Es decir, los cambios en los discursos que construyen la identidad comunitaria o grupal, producen cambios en la identidad y, por consiguiente, cambios en la estructura de pensamiento.

De esta manera, comenzarían a aparecer nuevas relaciones entre las partes que integran la comunidad, y entre la comunidad y el entorno relevante. La modificación de los discursos mentales sobre los cuales se establece la identidad individual, así como la introducción de nuevos discursos, hace que aparezcan nuevas relaciones sociales, las cuales producen cambios en la estructura de pensamiento, así como es posible que emerjan nuevas actividades con autonomía individual. El lenguaje afirmativo está orientado a la promoción de determinados grupos socialmente fragilizados, por lo cual la "igualdad pasa de ser simplemente un principio jurídico respetado de manera formal a todos, a considerarse como un objetivo constitucional a ser alcanzado por el Estado y la sociedad" (Barbosa, 2003, p. 22). De aquí que los discursos intervienen en la estructura de una comunidad. Los cambios relevantes en ellos o la introducción de nuevos cambios, modifican la estructura organizacional de la comunidad.

De esta manera, se pueden inducir transformaciones de orden cultural, pedagógico y psicológico, para sustraer del imaginario colectivo la idea de supremacía y de subordinación, de una clase social sobre la otra, o de una raza, o del hombre con relación a la mujer.

No obstante, algunas modificaciones en los discursos comunitarios o introducción de nuevos discursos no producen cambios en la identidad pero sí en la estructura, ya que aparecen nuevas relaciones en ella que hacen realidad las acciones desde los nuevos discursos. Por eso al ingresar a un grupo cultural, social, político o deportivo, se parte de un interés por reafirmar las identidades, se está en el grupo para ser, y durante la interacción social se generan procesos de interacción a partir de una experiencia "simbólica" en la que los miembros 
encuentran lo que les atrae, desde una perspectiva estética. Para Maffesoli (1990, p. 137) la estética puede ser entendida desde su etimología como "la facultad de sentir o experimentar”.

La experiencia estética de la identidad contiene varios elementos que la caracterizan en la dinámica de los grupos sociales, la diferencia marcada y en muchos casos radical, genera fenómenos que forman la persistencia de la exclusión social y su manifestación como virus mutante en constante transformación, que se propaga por las comunidades, la cual rehace los mapas conceptuales y recrea las prácticas sociales. Cada mundo mental se sostiene sobre concepciones distintas de procedencia. Detrás de cada una de ellas hay una metáfora que le aporta coherencia y sensibilidad, las metáforas funcionan como catalizadores del pensamiento y lo arraigan en los sentidos, y de este modo, preceden a los discursos teóricos y a las prácticas ciudadanas. Como dice Jorge Luis Borges, la historia no es otra cosa que la modulación de una metáfora.

La interacción simbólica producto de las dinámicas grupales, induce comportamientos colectivos, que orientan la búsqueda y conforman expectativas individuales. De su relación bullen metáforas que se construyen con el legado de distintas tradiciones, e ideologías que operan como matrices de pensamiento. Provienen de los procesos de estructuración individual con el mundo y la forma como se percibe la realidad. Tienen una implicación social, que al momento de aparecer subraya la ruptura de los lazos de unión que constituyen la desafiliación, y debilitamiento de la vida en relación con los demás. Supone formas de entenderse en relación con el otro y los otros, dadas a partir de la experiencia de la vida manifestada por el siguiente lenguaje «el quedar fuera y al margen», «el estar desviado, aislado, incomunicado, alienado, o disociado». También, aparece la evidencia en términos físicos, y biológicos, descrita como «estar asfixiado, ahogado, arrinconado, frente al abismo», para otros representa estar a la deriva, con el sentimiento del náufrago.

En términos de quien excluye, el lenguaje metafórico empleado tiene palabras como "pintao", "es de la otra orilla", "es un bicho raro", "Habla idioma diferente", "su voz no suena”, "está en otra frecuencia”, "sus palabras me resbalan”. De diferentes maneras se busca urbanizar la experiencia sobre la exclusión, que en todo momento aparece fundamentada y arraigada en las representaciones colectivas y los modelos mentales que las sostienen, influyendo de este modo en el comportamiento y la actitud humana. Así, el grupo social construye murallas conceptuales para representar los mecanismos estructurales que orillan y expulsan a los desechables. 
Estas son las partes que modelan la arquitectura de la exclusión. El sujeto excluido es tratado como un objeto, puede ser neutralizado y afectado emocionalmente por dichas circunstancias; lo cual incide en la percepción que tiene de sí mismo, y propicia la aparición de nuevos significados y proyectos vitales. Ser excluido significa la quiebra de los tejidos, que conforman el subsuelo de la vida humana y aseguran la protección, la confianza y la transmisión del sentido. Alude a la desconexión de los dinamismos sociales, de los intercambios productivos, o de la comunicación. Fenómeno retratado ya por Dostoievski, en una de sus novelas más controvertidas y polémicas: Memorias del Subsuelo, la cual tiene que ver con el hecho de que el protagonista de la novela sea un hombre anónimo, un individuo al que no le interesa decir su nombre, considerando más importante presentarse a sí mismo como funcionario.

Su rol social lo conduce en un juego de cargos y rangos sociales, hecho que lo lleva a experimentar una vida contradictoria y sometida, que reduce su vida a un plano formal y descriptivo que prescinde de la espontaneidad, del espíritu comunitario y la divergencia. Sin duda, es ya una crítica a la deshumanización de su época, especialmente merced a la división del trabajo y la "tabla de rangos".

Factor que indica que las circunstancias excluyentes pueden desplazar al sujeto e incidir de manera determinante en la forma como se concibe así mismo, y a los otros, pero que no lo predeterminan, ya que a pesar del peso de dichas tramas y marañas, las personas pueden reescribir su vida, y sacar un aprendizaje valioso para fundamentar su pensamiento y llegar a construir nuevas formas de lenguaje afirmativo.

Pero no se podrán generar cambios significativos si de la mano de implantar una mayor diversidad y una mayor representatividad de los grupo minoritarios, no se incorporan cambios en la economía del país, ya que no implementar acciones tendientes a ofrecer oportunidades de educación y trabajo para tales segmentos de la población, implica aceptar que las condiciones estructurales de la sociedad se mantendrán intactas, por lo que es fundamental iniciar procesos en diferentes direcciones, y de manera especial en lo que se denomina estructuras excluyentes del lenguaje.

\section{Las estructuras excluyentes del lenguaje}

Una de las maneras más usuales de producir el fenómeno de la exclusión, está en la forma como nos expresamos de determinados grupos o personas por razones de origen racial, etnia, sexo, edad, discapacidad, clase social y preferencias sexuales, entre otras. La más extendida en nuestra sociedad es la 
discriminación sexual, las mujeres por razón de su sexo, reciben un trato desigual y son segregadas al considerarlas inferiores a los hombres.

Históricamente el problema ha sido manejado como un hecho cultural, un problema de derechos humanos, atribuido a la pobreza y la falta de estabilidad de la democracia, reduciendo el fenómeno a la falta de políticas públicas y de manejo por parte del gobierno.

Pero sin duda, el problema tiene un trasfondo más complejo, ya que ha estado validado por la forma como nos expresamos frente a los otros y con personas del mismo sexo. De esta manera, en algún momento de nuestra vida, hemos discriminado y hemos sido discriminados con o sin una intención consciente, ya que es por medio del lenguaje que se reflejan, transmiten y refuerzan los estereotipos. El lenguaje no incluyente, toma la realidad a partir del género dominante como la única realidad, lo establece como el parámetro de lo humano, como lo universal sin considerar la realidad humana de los otros.

Puede verse evidenciado en el manejo de los duales aparentes, que son términos que adquieren significados diferentes según el sexo al que se refieran, la clase social, la cultura y la región de procedencia. Casi siempre tiene un carácter agresivo e insultante, en caso de zorro, haciendo relación al hombre como astuto, sagaz, inteligente, cuya valoración semántica es aceptada, y zorra, haciendo relación a mujer fácil, cuya connotación es negativa. Sucede lo mismo con cualquier y cualquiera, o aventurero y aventurera.

Se presenta también, la disimetría en los discursos, a partir del tratamiento desigual para las mujeres y para los hombres que dan lugar a diversos fenómenos, entre ellos los saltos semánticos, en los que se hace referencia sólo a un sexo de manera genérica, "los colombianos son personas alegres cuando están con su esposa y sus hijos”, se refiere sólo a los hombres, y genera exclusión hacia los demás. Otro fenómeno semántico se denomina la disimetría en la denominación, en la cual una persona es nombrada con la intención de conseguir menos renombre, mientras que quienes gozan de la posición social de poder, se resalta con mayor número de méritos $\mathrm{y}$ adjetivos calificativos.

El uso de diminutivos o adjetivos que impliquen inferioridad, menosprecio o desvalorización, y el uso de afirmaciones o frases estereotipadas que consoliden roles que desvaloricen y humillen a las personas. A nivel de género se emplean frases como: “las mujeres sirven sólo para dos cosas...”, “atienda a su esposo para eso es su mujer”, aunque el fenómeno se presenta también de modo contrario, "todos los hombres son iguales", “deje de llorar que parece niña”. En la siguiente tabla se presenta una relación de lo que son frases inadecuadas que encierran en su significado elementos de violencia, y la forma apropiada de emplearlas desde el lenguaje afirmativo para la paz. 
Tabla 2. Metáforas de Exclusión

\begin{tabular}{|c|}
\hline Metáforas de Exclusión \\
\hline Al filo de la navaja \\
\hline Una explosión de alegría \\
\hline Estar en la mira \\
\hline Estar al acecho \\
\hline Pelear por el éxito \\
\hline Morir de risa \\
\hline Estar en la trinchera \\
\hline Le salió el tiro por la culata \\
\hline Es un balazo \\
\hline Es pura dinamita \\
\hline Dar en el blanco \\
\hline Es un bala perdida \\
\hline Me clavó un puñal \\
\hline Es un arma de doble filo \\
\hline Hacer las primeras armas \\
\hline De armas tomar \\
\hline Armarse de paciencia \\
\hline Le tiró los dardos \\
\hline Armó una batalla campal \\
\hline Pasarlo bomba \\
\hline Salió disparado \\
\hline Le hizo una emboscada \\
\hline Estar entre la espada y la pared \\
\hline Estar en guardia \\
\hline Golpe de teléfono \\
\hline Fue un tiro de gracia \\
\hline La letra con sangre entra \\
\hline Armas inteligentes \\
\hline Golpe de gracia \\
\hline Retar a duelo \\
\hline Armarse de valor \\
\hline
\end{tabular}

Fuente: Elaboración propia 
Otro factor incidental, proviene de la gran cantidad de mensajes violentos que produce la cultura colombiana, y que genera un pensamiento distorsionado que se ha incrustado en la mente y opera como un motor cognitivo que acaba por automatizar la forma como percibimos y expresamos la realidad. Pero la dificultad no se halla exclusivamente en que los pensamientos distorsionados acaban siendo automáticos, la gravedad parte del momento en que, por nuestra familiaridad con ellos, olvidamos que son operativos. Así las personas excluyentes se convierten en un animal que tropieza con la misma piedra, una y otra vez, ya que cambiar la forma de pensar implica edificar con nuevas metáforas las ideas que dan sentido y explican la realidad de la mente.

Lo verdaderamente nocivo de los pensamientos distorsionados es su capacidad de camuflaje. Detrás de ellos hay una pesada carpeta de experiencias personales, interrelaciones sociales, influencias históricas-político-sociales, adiestramiento educacional, etc; sin embargo, determinan lo que una persona puede llegar a pensar y sentir, sin plantearse que pueden existir otras alternativas.

El camuflaje de las cogniciones distorsionadas también se manifiesta en el hecho de que aparecen ante nosotros como racionales. Lo que pensamos nos parece certero e incuestionable porque está pensado en términos absolutos, que no permiten mirar más allá en el horizonte. La sensación de que estamos ante una verdad total produce una especie de enajenación, las personas se entregan a ese pensamiento distorsionado y abandonan la posibilidad de razonar en otro sentido. La siguiente tabla, muestra dos perspectivas de abordar una situación desde los discursos, en la cual aparecen como determinante, el uso de las emociones.

Tabla 3. Narraciones excluyentes

\begin{tabular}{|l|l|}
\hline Emoción irracional & Acto de habla \\
\hline Ansiedad & $\begin{array}{l}\text { Si no arreglamos el problema no sé qué pueda suceder.... Porque } \\
\text { yo cuando me enfado... }\end{array}$ \\
\hline Depresión & $\begin{array}{l}\text { Nunca consigo lo que deseo, no valgo para nada, soy un perfecto } \\
\text { desastre en todo lo que me propongo. }\end{array}$ \\
\hline Culpabilidad & $\begin{array}{l}\text { Soy una mala persona, siempre le hago daño a la gente, lo llevo en } \\
\text { los genes. }\end{array}$ \\
\hline Vergüenza & $\begin{array}{l}\text { iQué vergüenza!, iqué van a pensar de usted!, habla de cosas sin } \\
\text { sentido que no le interesan a nadie. }\end{array}$ \\
\hline Ira & $\begin{array}{l}\text { ¡Nunca más volveré a quedar con él/ella, es insoportable i ¿ómo se } \\
\text { atreve a hacerme esperar tanto tiempo? No quiero saber nada de } \\
\text { él/ella. }\end{array}$ \\
\hline
\end{tabular}

Fuente: Elaboración propia 
Sin duda, como pensamos actuamos, lo que equivale a decir que para lograr una sociedad libre del lenguaje excluyente y violento, es indispensable la amplia concientización de la propia sociedad, de lo contrario es aceptar que dicho mal se ahonde, y se vuelva una frontera invisible de la sociedad y de las relaciones humanas, produciendo el fenómeno de distanciamiento social.

\section{Tan cerca, tan lejos: la distancia social}

La distancia social se establece en forma de fronteras físicas y simbólicas, producto de la representación cognitiva del pensamiento, su influencia produce el fenómeno de la frontera, acompañada del distanciamiento social. La frontera es el resultado de las representaciones cognitivas que las personas tienen o guardan respecto al otro, al que considera diferente, su institucionalización traza un margen imaginario que altera la proxémica y la kinésica expresiva dada a partir de la producción de enclaves territoriales, que se evidencian mediante mecanismos expulsores.

La exclusión al ser un mecanismo que aparece asociado a las formas de representación social y colectiva, también se encasilla en ciertos lugares, con grupos poblacionales específicos. Al estar condicionado por la palabra y el uso de las metáforas, tienen un impacto directo en las relaciones sociales, que pueden cristalizarse de manera dramática en la desestructuración psico-emocional, en la ruptura de los lazos de unión vecinal, en la perspectiva de futuro, y en la aparición de anclajes radicales de pensamiento.

El uso de metáforas de exclusión, no sólo nos impide ver el mudo de otra manera, sino que produce un efecto doble, con relación a los otros, surge el extrañamiento, lo entraño; y con relación a uno mismo, el fenómeno del extranjero. Los extraños son personas que no conocemos, que están fuera de nuestro alcance interpretativo, a quienes no comprendemos ni entendemos, por su parte el extranjero como lo representa Albert Camus, es aquella persona que se despersonaliza de la realidad, y por lo tanto vive por inercia, todo lo hace solo por hacerlo, no expresa ningún sentimiento de ningún tipo, ni odio, ni repugnancia, ni felicidad, ni amor, simplemente indiferente ante todo y todos.

El fenómeno se complejiza, al ser conscientes que la sociedad plural y multicultural, no solo genera un sinnúmero de extranjeros y extraños, los cuales cada vez en más difícil que encajen en nuestro mapa cognitivo, moral y estético. Lo cual puede llevar a la aparición de ciertas enfermedades mentales como la topofobia, (miedo irracional y enfermizo a ciertos lugares y situaciones), la xenofobia (miedo al extranjero), y la aporofobia» (miedo al pobre). 
Este fenómeno puede hacerse mucho más crítico, profundo y conflictivo en las relaciones humanas, cuando aparecen mecanismos de defensa hacía la exclusión producto de la psicosis social, entre ellos la desaparición física, la limpieza social, y el repudio. También es frecuente la "satanización” del extraño, a quien se suele culpar de todos los males de la sociedad, y aparece reflejado en todos los relatos con una connotación negativa. Fenómeno que sucedió en los Estados Unidos, en los que siempre se asociaba a las personas afro descendientes con drogadictos, delincuentes y asesinos.

Otro mecanismo más sutil, pero no menos empleado, es la reducción instrumental del extraño a recurso productivo. Nos fijamos en la pobreza porque nos permite diferenciarnos socialmente, pensamos en los marginados cuando se trata de realizar trabajos desagradables e indignos, y los aceptamos mientras sobrevivan en calles marginales y miserables, pero cuando aparecen en los restaurantes o almacenes de compras, nos hiere y nos ofende. En total, su presencia es aceptada mientras se mantengan en los submundo urbanos. Dostoievski plantea en las Memorias del Subsuelo, la experiencia de dos sujetos que ostentan grandes desigualdades sociales, y cuyo resultado es el choque, la confrontación, abrupta y sin razón, producto de las etiquetas sociales, y que sin duda también se emplean para la designación de los espacios, como se explicará a continuación.

\section{Submundos, suburbios y marginalizados}

Al igual que se crean metáforas para determinar al excluido, también se construyen metáforas espaciales, para focalizar la marginalización y territorializarla. Parte de la raíz de dicho pensamiento, proviene de la forma como históricamente se ha organizado la sociedad en el urbanismo, pensada con un centro y una periferia, en la cual la vivienda se ha valorizado de la misma manera, en el centro están los más adinerados y en las afueras los sectores más pobres de la ciudad. Dicha condición tienen una relación directa con los factores de producción y consumo, trabajo y autonomía.

No estar dentro de la lógica del modelo de producción y consumo, significa perder la identidad personal, quedar en el grado máximo de exclusión, y recibir la connotación que tiene la sociedad para aquellos que lindan por dicho territorio. Esa es una de las más graves y agresivas formas de exclusión que persisten y que la sociedad tolera ya que es la primera exigencia para hacer parte de la sociedad. 


\section{El lenguaje de exclusión y su funcionamiento cognitivo}

En este punto de la cuestión se puede afirmar que las formas de expresión y de habla son el resultado del aprendizaje lingüístico, dado a partir de la adquisición de "control consciente" y no "habitual" sobre los patrones fonológicos, gramaticales y léxico-semánticos de la lengua. Este hecho se sustenta sobre la idea de que el funcionamiento cognitivo de un sujeto o de un grupo de sujetos en situación reposa sobre el repertorio de esquemas disponibles, anteriormente formados, y que al mismo tiempo se va dando el descubrimiento de nuevos aspectos, que forman nuevos esquemas en situación.

Pero no se puede desconocer que las conductas se basan en el repertorio inicial de los esquemas disponibles, y la posibilidad o no que tiene una persona de tener un desarrollo cognitivo, sólo es posible a través de la ampliación de los campos conceptuales. Cuando dichos campos conservan anclajes de lenguaje en los que predominan palabras o frases de exclusión, se conserva dicho comportamiento en la interacción social.

Este planteamiento rechaza el sustento teórico del "audiolingualismo" y las propias teorías que lo fundamentan, también la capacidad innata de adquisición $\mathrm{y}$ un aspecto creador de su uso, resaltando por el contrario una fuerte insistencia en la enseñanza de la gramática de la lengua frente a la negación de este principio en la hipótesis mecanicista, desde la cual, la sociedad asume que las personas incorporan el lenguaje mediante actos de repetición y escucha, pero ello no permite realizar un cuestionamiento sobre el significado y sentido de determinadas frases culturales, que se traspasan de generación en generación, y que llevan formas de exclusión y violencia anidadas en su estructura gramatical. Este párrafo es confuso.

Así, la operacionalidad de un concepto debe ser experimentada por medio de situaciones variadas, y para su aprendizaje se deben analizar una gran variedad de conductas y de esquemas para comprender en qué consiste, "desde el punto de vista cognitivo, tal o cual concepto: por ejemplo, el concepto de razón no se comprende sino a través de una diversidad de problemas prácticos y teóricos; igual ocurre con los conceptos de función o de número". (Gérard Vergnaud, 1990).

Una de las líneas de investigación que más ha ejercido su influencia en el establecimiento de presupuestos generales en el marco de esta hipótesis es aquella que propone un modelo cognitivo basado en la teoría del aprendizaje significativo por descubrimiento de D. Ausubel (1976). 
La noción de una jerarquía de la significación, implícita en la obra de Ausubel, añade una nueva dimensión a la necesidad de un aprendizaje significativo que rompa con la fórmula mecanicista, y les permita a las personas realizar procesos creativos de construcción del habla, siendo plenamente conscientes de su sentido. Así, la existencia de una jerarquía en la organización cognitiva implica la posibilidad de organizar los actos de habla en la vida cotidiana de acuerdo con tal jerarquía.

Es interesante destacar que, desde un punto de vista lingüístico, el concepto de "significatividad" presenta -en las metáforas y narraciones encontradasgrandes lagunas. Sin embargo, resulta esperanzador el hecho de que desde las últimas formulaciones del chomskismo en general, y las aportaciones de la semántica generativa en particular, se puede (pueden) señalar las conexiones entre los procesos semánticos y el funcionamiento de la estructura cognitiva del ser humano. En términos de "código" y "mensajes”, se podría afirmar que las unidades que hacen referencia al código (reglas sintácticas, morfológicas y fonológicas) resultan "inestables" a menos que puedan relacionarse directamente con los mensajes (categorías semánticas, básicas y universales) subsumido por factores semánticos. Lo que indica que las personas, al usar metáforas en frases como: "Armó una batalla campal”, "salió disparado”, o "Estar entre la espada y la pared", no son conscientes del efecto socio-cultural que generan.

La revelación más importante desde el enfoque comunicativo de los contenidos de las metáforas y narraciones recopiladas, es aquella que manifiesta que no se trata sólo de aprender a repetir oraciones, sino que se necesita también aprender a realizar, de forma apropiada y coherente, los actos del lenguaje que intervienen en las situaciones de la comunicación. Como sabemos, el contenido del enunciado puede analizarse por medio de diferentes tipos de predicaciones engranadas entre sí. Bajo un enfoque comunicativo se insiste sobre los elementos del enunciado que poseen una función esencialmente "comunicativa” en oposición al contenido proposicional de función "referencial” que ha recibido un tratamiento sistemático y con una directa influencia conductistas y mentalista.

En este sentido, culturalmente se identifica la ausencia de mecanismos que le proporcionen a las personas, "los medios para construir una personalidad como sujeto hablante en la lengua que aprende” (en Coste et al., 1976: 88). Entre ellos están la ausencia de actividades comunicativas construidas desde la perspectiva de criterios negociados y abiertos, en las que los usos lingüísticos que se pretenden desarrollar posean un carácter indefinido e ilimitado -en la medida que emanen de las necesidades de usos lingüísticos originadas por la realidad del 
proceso de comunicación global-, y donde la atención a la diversidad ocupe un lugar pedagógicamente relevante.

También se identificó la ausencia de tramas de desarrollo creativo, en función de una dirección más humanística, sociocultural y holística, que atienda no sólo al tema de la comunicación sino también a cuestiones de la co/comunicación, y que además de la dimensión cognitiva- se plantee involucrar en el aprendizaje del lenguaje aspectos de la personalidad de quien la aprende, a fin de contribuir en su desarrollo integral como persona (autoestima, capacidad crítica, autonomía, equilibrio afectivo y social, actitudes para la convivencia, destrezas para afrontar la diversidad lingüística y cultural, etc.).

En definitiva, hace falta una orientación decisiva hacia la función educativa del aprendizaje más centrada en las programaciones analíticas en los procesos de significación que en las formas lingüísticas.

\section{Conclusiones}

Tras el análisis de las narrativas y metáforas de la exclusión en actos de habla, es posible establecer algunas precisiones sobre el tema.

En primer lugar, la existencia de estructuras excluyentes en el lenguaje, que inciden en la forma de percibir al otro, determinarlo y relacionarse, y que aparecen enmascaradas culturalmente en formas semánticas y pragmáticas, tales como: el manejo de los duales aparentes, el uso de diminutivos o adjetivos, el lenguaje sexual, el camuflaje de las cogniciones distorsionadas y la disimetría en los discursos. Para Bel Adell (2002) la exclusión es una manifestación, expresión y resultado de una determinada estructura social, que juega un papel determinante y en ocasiones decisivo, siendo la sociedad la que forma en su interior poblaciones "sobrantes" y formas simbólicas en el lenguaje para estigmatizarlas, como en el caso de los "ñeros" o "desechables" para referirse a personas en condiciones de pobreza extrema.

En segundo lugar, que el uso pragmático del lenguaje tiene cargas semánticas de exclusión social que establecen fronteras que inciden en las relaciones humanas, y que a su vez crea territorialización geográfica de la exclusión. Rizo y Romeu, (2006) han denominado a este fenómeno "frontera interna", entendido como un "lugar simbólico donde simultánea y dialécticamente se producen y reproducen los significados con los que el sujeto se percibe a sí mismo y a los 
otros, y por medio de los cuales aprehende el mundo que le rodea”. La frontera interna hace alusión al universo simbólico de los sujetos y grupos, y en su construcción "intervienen elementos socioculturales, históricos, ideológicos y cognitivos, así como psicológicos, afectivos, emotivos y epistemológicos”.

Finalmente, se determina que las metáforas y discursos de exclusión son producto de un repertorio de esquemas disponibles, anteriormente formados por el individuo y la cultura, y que no varía sin la aplicación de estímulos de aprendizaje que fomenten el uso de nuevas metáforas conceptuales y marcos cognitivos. Dice Vergnaud (1990) el conocimiento racional es operatorio, indica que existen situaciones para las cuales "el sujeto dispone de su repertorio, en un momento dado de su desarrollo y bajo ciertas circunstancias". Siendo las metáforas de exclusión una respuesta del repertorio lingüístico de raíz cognitiva, producto de un proceso de adquisición de "control consciente" del lenguaje sobre los patrones fonológicos, gramaticales y léxico-semánticos.

\section{Bibliografia}

Abellán, J.L. (1994): Una cultura para la paz. Ideas para el siglo XXI. Ed. Libertarias, Madrid.

Atkfnson, R. C., y Shiffrin, R.M. (1968). Human memory: A proposed system and its control processes. En K.W. Spence y J. T. Spence (Eds.). The psychology of learning and motivation. New York: Academic Press.

Ausubel, D. P. (1976). Psicología educativa. México: Trillas.

Baddeley, A. y Hitch, G. (1974). Working memory. In G.A. Bower. En K.W. Spence y J. T. Spence (Eds.). The psychology of learning and motivation. New York: Academic Press (pp. 47-89). New York: Academic Press.

Baddeley, A. D. y Lieberman, K. (1980). Spatial working memory. En R. S. Nickerson (Ed.). Attention and performance VIII (pp. 521-539). Hillsdale, New Jersey: Lawrence Erlbaum.

Bandura, A. (1987): Pensamiento y Acción. Fundamentos sociales, Barcelona, Martínez Roca.

Beck, J. (2000). Terapia cognitiva: conceptos básicos y profundiación . Madrid: Gedisa. 
Bilbeny, N. (1997): La revolución en la ética. Anagrama, Barcelona.

Burr, Viven. (2002). Psicología Discursiva. En The Person in Social Psychology (cap. 5). Psychology Press, United Kingdom,

Bilfltleley, A. D. (1976). The psychology of memory. New York: Hamer and Row.

Broadbent, D. E. (1983). Percepción y comunicación. Madrid, España: Debate.

Charaudeau, P. (2011). Las emociones como efecto de discurso. Revista Estudios de Comunicación y Política. Universidad Autónoma Metropolitana.

Corbett, J. (1999). Special needs and clients rights: the changing social and political context of special educational research. British Journal of special education (378-389).

Cortina, A. (2000). Aporofobia. El País.

Coste, D. et al (1976). Un niveau - seuil. Strasbourg: Conseil de L'Europe.

Chomsky, N. (1968). Language and mind. New York. Harcourt Brace and World.

Chomsky, N. (1988) Language and problems of Knowledge. Cambridge, Mass. The MIT Press.

Delors, J. (1996). La educación encierra un tesoro. Informe de la Comisión Internacional para la Educación del siglo XXI. Santillana/UNESCO, Madrid.

Echeverría, R. (1994). Ontología del lenguaje. Ediciones pedagógicas chilenas.

Fraser, N. (1993). Repensar el ámbito público: una contribución a la crítica de la democracia realmente existente. Debate Feminista, (7), 23-57.

Fraser, N. (1997). I ustitia Interrupta. Reflexiones críticas desde la posición "postsocialista". Siglo de Hombre Editores, Universidad de los Andes.

Garrido, E., y Vega, M. (1993). Diferencias entre la percepción social de las conductas negativas morales e intelectuales. En I. Fernández e I. Martínez (Eds.). Epistemología y procesos psicosociales básicos. Sevilla: Eudema. 
Gumperz, J. y Dell H. (1964). The ethnography of communication. American Antropologist, 66. (6), parte 2.

Geertz, C. (2009). La interpretación de las culturas. Editorial Gedisa. Barcelona. España.

Halliday, M.A. K, (1982). El lenguaje como semiótica social. México: Fondo de Cultura Económica.

Hymes, D. (1971). Competence and performance in linguistic theory. Acquisition of languages: Models and methods. Academic Press, (3), 23. Ed. Huxley and E. Ingram. New York:

Hymes, D. (1972). On communicative competence. En Pride, J.B. y J. Holmes (Eds.). Sociolinguistics (69-293). Londres: Penguin Books.

Lave, J. y Etienne W. (1991). Situated Learning: Legitimate Peripheral Participation. Cambridge: Cambridge University Press.

Jares, X. (2000): Educación y conflicto. Ed. Popular, Madrid.

José, M. C. (1998). Dimensiones simbólicas de la participación juvenil, la experiencia de dos grupos en Bogotá. Bogotá: Formación de investigadores: estudios sociales y propuestas de futuro.

Martín-Barbero, J. (2007). Reconfiguraciones de lo público y nuevas ciudadanías. En J. E. González (Ed.). Ciudadanía y Cultura (pp.11 - 37). Bogotá: Universidad Nacional de Colombia.

Martínez, M. (1995). La educación moral: una necesidad en las sociedades plurales y democráticas. Revista Iberoamericana de Educación, (7), 13-40.

Melucci, A. (1998). La experiencia individual y los temas globales en una sociedad planetaria. Madrd: Trotta.

Miller, G. A. (1956). The Magical Number Seven, Plus or Minus Two: Some Limits on Our Capacity for Processing Information. The Psychological Review, (63), 81-97.

Rizo y Romeu (2008). El habitus y la intersubjetividad como conceptos clave para la comprensión de las fronteras internas. Un acercamiento desde las propuestas teóricas de Bourdieu y Schütz. Frontera norte, 21(41). México. 
Roland, B. (1980). En $S / Z$ (pág. 3). México: Siglo XXI.

Rubio Carracedo, J. (1992): Ética constructiva y autonomía moral. Tecnos, Madrid.

Patrick, C. (2001). Las emociones como afecto de discurso. Revista Electrónica Estudios de Comunicación y Política. Universidad Autónoma Metropolitana.

Perez, A. (2008). Reggeatón: Manifestación artística de los marginados. The University of texas at San Antonio. Department of Modern Languages and Literatures.

Vergnaud, G. (1990). La teoría de los campos conceptuales. Université René Descartes, $10(2-3), 133-170$.

Pole, D. (1982). El concepto de razón. En Dearden, R.F., Hirst, P.H., Peters, R.S. Educación y desarrollo de la razón. Formación del sentido crítico (pp. 149-173). Narcea, Madrid.

Salomon, G. (Ed.) (1993). Distributed Cognitions: Psychological and Educational Considerations, Cambridge University Press, Cambridge, United Kingdom.

Sánchez, C. (1993). Una mirada a la palabra desechable. El Espectador, No 544, 26 de septiembre, p.8. Bogotá.

Sperling, G. (1960). The information available in brief visual presentations. Psychological Monograpl $\sim$ s, 74(11).

Searle, J. (1993). Actos de habla. México, Planeta Agostini.

Tarrow, S. (2004). El poder en movimiento. Los movimientos sociales, la acción colectiva y la política. España: Alianza.

Viven, B. (2002). Psicología Discursiva. The Person in Social Psychology.

VV.AA. (2001): Educar desde y para la paz. Fund. Fernando Rielo, Madrid.

Zambrano, $\mathrm{M}^{\mathrm{a}}$ (1994): Los peligros de la paz, Las palabras del regreso. Amaru Ed., Salamanca. 